\title{
EDUCAÇÃO DO CAMPO: UMA ANÁLISE SOBRE O HISTÓRICO E A FORMAÇÃO DE PROFESSORES NO MUNICÍPIO DE ARRAIAS (TO)
}

\section{EDUCACIÓN RURAL: UN ANÁLISIS DEL HITÓRICO DE LA FORMACIÓN DE PROFESORES EN EL MUNICIPIO DE ARRAIAS (TO)}

\author{
SILVA, Géssica Pereira da ${ }^{1}$ \\ SANTOS, Ana Roseli Paes dos ${ }^{2}$
}

\begin{abstract}
RESUMO:
Observando a história dos avanços e dos desafios da educação do campo e,ao refletirmos sobre esse histórico, no contexto tocantinense, sobre a formação docente para 0 campo,surgiu a necessidade de desenvolver um estudo qualitativo que pudesse elucidar: a) o papel dos educadores do campo; b) a distinção entre os termos 'educação rural' e 'educação do campo'; c) a contribuição dos movimentos sociais para esse sistema educacional; d) o que representa esse novo modelo; e, ainda, quais as melhorias possíveis apontadas para os sujeitos do campo? Estas são as questões que, esclarecidas, podem mudar o rumo dessa história e agregar valor à cultura campesina, quebrando os preconceitos sobre os sujeitos do meio rural em comparação ao meio urbano.
\end{abstract}

Palavras-chave: Educação do Campo; Escola do Campo; Formação de professores; História da educação campesina no Município de Arraias (TO).

\section{RESUMEN:}

Observando la historia de avances y desafíos de la educación del campo e, reflexionando sobre su historia, en el contexto de Tocantins para la formación de docentes en el campo, vino la necesidad de desarrollar un estudio cualitativo que podría demostrar: a) el papel de los educadores del campo; b) la distinción entre los términos "educación rural" y "educación campesina"; c) la contribución de los movimientos sociales hacia este sistema educativo; d) ¿qué representa este nuevo modelo; y también qué posibles mejoras están dirigidas al estudiante del campo? Estas son las preguntas que, si aclaradas, pueden cambiar el curso de esta historia y añadir valor a la cultura campesina, rompiendo los prejuicios sobre las personas de las zonas rurales en comparación a las de las zonas urbanas.

Palabras clave: Educación campesina; Escuela del Campo; Formación de profesores; Historia de la educación campesina en el Municipio de Arraias (TO).

${ }^{1}$ Aluna do Curso de Licenciatura em Educação do Campo com habilitação em Artes Visuais e Música, na Universidade Federal do Tocantins. Av. Juraíldes de Sena e Abreu, Setor Buritizinho, 77330-000, Arraias-TO. E-mail: <gessicapereira@mail.uft.edu.br>

${ }^{2}$ Professora Assistente do Curso de Licenciatura em Educação do Campo com habilitação em Artes Visuais e Música,na Universidade Federal do Tocantins. Av. Juraíldes de Sena e Abreu, Setor Buritizinho, 77330-000, Arraias-TO. E-mail:<anaroseli@mail.uft.edu.br> 


\section{INTRODUÇÃO}

A educação do campo passou por transformações nas últimas décadas, sem perder de vista a sua característica de resistência. Ela nasceu das lutas da população rural, dos trabalhadores do campo em conjunto com movimentos sociais do campo, que têm como objetivo valorizar a cultura, as crenças, a terra, o meio social, o meio ambiente e, sobretudo, a identidade do homem campesino.

A Constituição Brasileira (BRASIL, 1988) assegura que a Educação é direito de todos e dever do Estado, mas essa conquista parece ser esquecida e silenciada quando se trata do campo. A Constituição reza, também, que o aluno tem o direito de estudar em uma escola próxima a sua residência. Entretanto, pouco se fala e se estuda sobre a situação das escolas do campo.Para mais bem entendermos essa situação recorremos a Arroyo, Caldart e Molina que afirmam que:"somente $2 \%$ das pesquisas dizem respeito a questões do campo, não chegando a $1 \%$ as que tratam especificamente da escola no meio rural"(ARROYO et al., 2008, p.8).

Segundo Martins (2009, p.11), a problemática enfrentada pelas escolas rurais está na precariedade e nas condições em que se encontram, seja o espaço físico, seja pela formação insuficiente dos professores, acentuando ainda mais a problemática e a diferença em torno da educação no campo, em comparação coma urbana. Ainda de acordo com Arroyoet al.(2008, p.11),é essa visão preconceituosa que faz com que os direitos pela educação sejam tratados com descaso, pois o campo é visto como lugar de atraso, confirmando a indiferença com que é tratada a educação do e no campo. É em busca por direitos iguais que os trabalhadores e as comunidades rurais lutam para garantir o acesso à educação.

\section{EDUCAÇÃO DO CAMPO: VALORIZAÇÃO SOCIAL}

Podemos observar, nos estudos já realizados, que os trabalhadores do campo lutam não apenas por uma educação de qualidade, mas também por sua valorização 


\section{CRIAR EDUCAÇÃO}

Revista do Programa de Pós-Graduação em Educação - UNESC
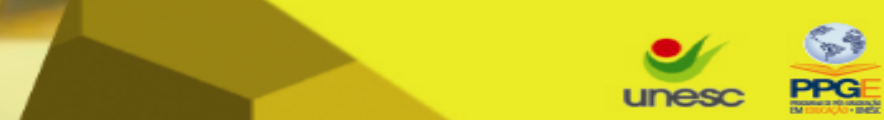

como ser humano, tentando quebrar as barreiras do olhar preconceituoso sobre o campo, sobre o camponês. Lutam por essa conquista através da coletividade e em parceira com movimentos sociais do campo.

O Movimento Social dos Trabalhadores Sem-Terra(MST)tem reclamado por políticas públicas que visem melhorias para as comunidades rurais e para os assentamentos e acampamentos dos sem-terra. Essas políticas visam, sobretudo, a valorização social do camponês, a reforma agrária e a educação no e para o campo. Vincula-se a essa demanda o Programa Nacional de Educação na Reforma Agrária (PRONERA), que nasceu em 1998, como resultado de luta dos movimentos sociais, dos sindicatos de trabalhadores rurais e do governo brasileiro para desenvolver políticas públicas de educação do campo, desenvolvida principalmente em áreas onde já se efetivou o assentamento, com o objetivo de fortalecer o mundo campesino enquanto território ativo e vivo em todas as dimensões: sociais, culturais, econômicas, ambientais, políticas e étnicas.

\section{A FORMAÇÃO DE PROFESSORES E EDUCAÇÃO DO CAMPO NO MUNICÍPIO DE ARRAIAS (TO)}

Para entendermos a história da educação do campo, em Arraias, é preciso falar sobre a criação da Universidade Federal do Tocantins (UFT) e da implantação da Licenciatura em Educação do Campo, no Campusde Arraias. A criação da UFT foi

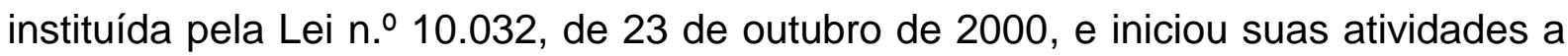
partir de maio de 2003. Desde o momento germinal até a implantação da UFT, foram levadas em consideração as características das gentes que povoam o Estado. Assim, o Tocantins é um Estado novo, criado em 1ํㅡ de janeiro de 1989 e se caracteriza por ser um Estado multicultural (indígenas, afro-descentes e pessoas vindas de outros estados do país). O caráter heterogêneo de sua população coloca para a UFT o desafio de promover práticas educativas que elevem o nível de qualidade de vida, dê oportunidades iguais e respeite as características próprias da sua população.

Criar Educação, Criciúma, v. 6, nº1, julho/novembro 2016.- PPGE - UNESC 
Portanto, a estrutura da universidade é multicampi, ou seja, com campusdispersos entre o norte e o sul do estado. São sete campi universitários localizados em regiões estratégicas do Estado, que oferecem diferentes cursos vocacionados para a realidade local, implantados em diferentes cidades a partir do Norte em direção ao Sul: Tocantinópolis, Araguaína, Miracema, Palmas, Porto Nacional, Gurupi e Arraias.

Desse modo, a educação do campo, no Município de Arraias (TO), deu-se a partir da aprovação do curso de Licenciatura em Educação do Campo, com habilitação em Artes Visuais e Música, em 2014. Este curso se diferencia dos seus similares de outras instituições que o oferecem, em áreas ligadas às ciências agrárias, biológicas ou exatas. O objetivo do curso é promover uma formação multidisciplinar de professores, com base na Pedagogia da Alternância, para proporcionar a expansão da oferta da educação básica nas comunidades rurais, atender à demanda apresentada no campo, local em que há carência de professores qualificados para o ensino de diversas áreas, especialmente Artes e Música; além do auxílio à superação das desvantagens educacionais, observando os princípios de igualdade e gratuidade quanto às condições de acesso. A operacionalização do curso se dá por meio da organização de dezoito turmas com núcleos de estudos básicos, o que significa que, a cada ano, entram duas turmas de 60 estudantes.

A demanda de interessados no curso é alta; o número de inscrições para os vestibulares passou de 700 para as 120 vagas ofertadas. Pode-se observar que aos poucos a Educação do Campo no Campus de Arraias está se firmando e se destacando em relação aos demais cursos ofertados pelo campus. Apostando nessa demanda implantou-se, também, o curso de Especialização em Educação do Campo com vistas a atender, não só, mas especialmente, aos professores das escolas das zonas rurais, promovendo uma formação continuada.

Dessa forma, as escolas do campo do município e as práticas pedagógicas que acontecem ali, que até então não tinham visibilidade nem muita atenção por parte das secretarias e delegacias de ensino da região, tornaram-se objeto de estudo por parte da comunidade acadêmica. Estão na pauta das pesquisas a nucleação, as classes multisseriadas, a formação insuficiente dos professores, a infraestrutura das escolas, os materiais pedagógicos, o transporte escolar, a merenda escolar, a 


\section{CRIAR EDUCAÇÃO}

Revista do Programa de Pós-Graduação em Educação - UNESC
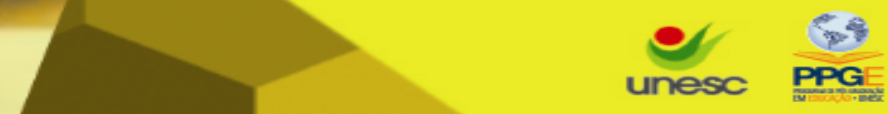

proposta do regime de alternância, a evasão escolar, as dificuldades de aprendizagem, dentre outros assuntos. Todos estes temas de pesquisa desvelam a situação da educação que acontece na zona rural do município de Arraias, no Estado de Tocantins.

Entretanto, mais preocupante é a existência de milhares de funções docentes sendo exercidas por professores que têm apenas o ensino fundamental e que, portanto, não dispõem da habilitação mínima para o desempenho de suas atividades.

\section{ENTRE A EDUCAÇÃO DO CAMPO E A EDUCAÇÃO RURAL}

Nos últimos 150 anos a educação institucionalizada esteve subordinada ao modo de produção capitalista, centrada no propósito de fornecer conhecimento e pessoal necessários à máquina do capital em favor do sistema de sua expansão. E ainda de gerar e produzir um quadro de valores morais que validem os interesses dominantes, por meio da "dominação estrutural" implacavelmente imposta. (MÉSZAROS, 2005)

Desse modo, configurou-se a educação rural no Brasil, nas primeiras décadas do século XX, destinada à classe de trabalhadores da zona rural. Essa educação tem por base a fundamentação filosófica do assistencialismo, do pensamento latifundialista empresarial, do controle político sobre a terra e as pessoas que nela vivem, e no ideário da oligarquia agrária. Um tipo de educação utilitarista em que os conhecimentos não precisavam de um aprofundamento de conteúdos e sim, apenas, de algumas instruções que pudessem garantir a essa gente tirar da terra o seu próprio sustento, garantir a fixação do homem no campo para que servisse de mão de obra barata para as lavouras dos grandes latifúndios.

No entanto, esta proposta de educação está totalmente desvinculada dos propósitos da população que vive no e do campo; é neste contexto que os povos do campo começaram a reivindicar, dentre outros direitos sociais, o direito a uma política educacional específica e diferenciada para o campo. Fortalecidos pelos movimentos sociais e populares, após um longo período de resistência e de 


\title{
CRIAR EDUCAÇÃO
}

Revista do Programa de Pós-Graduação em Educação - UNESC

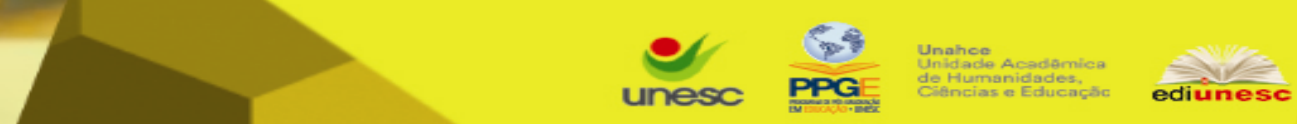

reivindicações,obtiveram uma significativa conquista com a promulgação de políticas de educação para as áreas de reforma agrária.

Nasce, assim, um novo conceito de educação para contrapor a educação rural, isto é, a "educação do campo".Para Arroyoet al.,

\begin{abstract}
Esta visão do campo como espaço que tem suas particularidades e que é ao mesmo tempo um campo de possibilidades da relação dos seres humanos com a produção das condições de sua existência social, confere à Educação do Campo o papel de fomentar reflexões sobre um novo projeto de desenvolvimento e o papel do campo neste projeto. Também o papel de fortalecer a identidade e a autonomia das populações do campo e ajudar o povo brasileiro a compreender que não há uma hierarquia, mas uma complementaridade: cidade não vive sem campo que não vive sem cidade(ARROYO et al., 2005, p.15, grifo dos autores).
\end{abstract}

Na compreensão de Caldart, os povos do campo devem ser atendidos por políticas de educação que garantam seu direito a uma educação que seja no e do campo e esclarece:

No [campo]: o povo tem direito a ser educado no lugar onde vive; Do [campo]: o povo tem direito a uma educação pensada desde o seu lugar e com a sua participação, vinculada à sua cultura e às suas necessidades humanas e sociais (CALDART, 2002, p.18).

Então, de acordo com tal premissa, podemos observar os avanços e os desafios da educação do campo ao longo de sua história, ao refletirmos sobre:'O que é educação do campo?', 'Qual é o seu histórico no contexto tocantinense?', e também sobre a formação de professores para a educação do campo.

\section{METODOLOGIA}

Esta é uma investigação qualitativa, pois tem um enfoque multimetodológico com abordagem interpretativa e naturalística. Isto significa estudar o fenômeno no seu contexto natural tentando compreendê-lo segundo os significados que as pessoas atribuem a ele. Implica dizer que, para a realização desta investigação foram consideradas duas dimensões particulares da educação do campo no município de Arraias (TO): uma respeitante ao caráter histórico da educação do campo nesse 


\section{CRIAR EDUCAÇÃO}

Revista do Programa de Pós-Graduação em Educação - UNESC

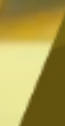

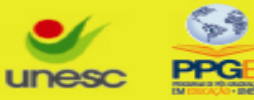

contexto e a outra a formação de professores para as escolas rurais. Assim, para realizar esta investigação optou-se pela pesquisa documental porque esta é uma pesquisa empírica que, entre outros objetivos, investiga um fenômeno contemporâneo dentro de seu contexto real; neste caso o histórico e a formação de professores do campo no município de Arraias (TO).

Esta opção foi determinada, em primeiro lugar, pelas limitações de tempo inerentes a um trabalho desta natureza (uma monografia) o que inviabilizaria, por exemplo, a utilização de um desenho etnográfico que requer do pesquisar um tempo maior no terreno. A coleta dos dados envolveu a consulta a documentos e a relatório da Secretaria de Educação do Município, da Delegacia Regional de Educação e da Universidade Federal do Tocantins, Campusde Arraias(discursos, legislação, relatórios, atas, regulamentos, manuais, recortes jornais, documentos de estágio etc.).

\section{RESULTADOS E DISCUSSÃO}

A pesquisa apurou que a maioria dos professores que atuam nas escolas do campo do município de Arraias tem apenas a educação fundamental, habilitação insuficiente para exercer docência. No entanto, estes são os únicos profissionais que se interessam em trabalhar na zona rural, sendo muitos deles membros da comunidade onde a escola está inserida. A falta de interesse de profissionais mais bem qualificados é justificada, por um lado, pela inviabilidade de se deslocar para estas escolas por estradas de terra e sem condução que chegue até as comunidades, pelas grandes distâncias entre as localidades e, por outro, pela baixa remuneração e pelas condições precárias em que se encontram muitas escolas - da infraestrutura à falta de material didático.

Consideramos que os dados desta pesquisa podem contribuir, efetivamente, para melhoria da formação, o que por si só não resolverá os problemas que enfrentam as escolas rurais. A Universidade Federal do Tocantins, especificamente os Campi de Arraias e de Tocantinópolis, recentemente inaugurou um curso de Licenciatura em Educação do Campo com vistas a atender à necessidade de uma formação mais Criar Educação, Criciúma, v. 6, no1, julho/novembro 2016.- PPGE - UNESC 
sólida e suficiente de docentes para o campo. Este é um curso relativamente novo no país, um curso que veio para valorizar o homem do campo e atender as suas demandas. O objetivo é respondera os anseios, do camponês, de acesso a uma formação acadêmica. A formação dos professores do campo segue uma especificidade diferenciada, vai além de uma simples formação de professores, pois ela é a composição de profissionais que vão educar pessoas, cujas necessidades específicas têm por base a valorização social e cultural das gentes de comunidades rurais. Sendo assim, o perfil do educador do campo exige uma compreensão de qual é o seu papel nesses contextos. Nesse sentido, esta formação deve articular a preparação para a gestão dos processos educativos escolares e os processos educativos comunitários. Podemos observar que na proposta do Curso de Licenciatura em Educação do Campo da UFT existe uma preocupação com a formação de um tipo de educador que tem em suas mãos a missão de fazer com que o educando possa visualizar que a sua comunidade é capaz de the oferecer uma educação de qualidade, no mesmo nível da educação urbana, e, sobretudo valorizar os saberes populares dos povos do campo.

\section{CONCLUSÃO}

O presente trabalho buscou como foco fazer uma breve análise da situação da educação do campo e da formação dos professores que atuam nas escolas da zona rural do Município de Arraias (TO). A primeira constatação foi a de que a educação do campo é basicamente vincada por lutas das populações rurais juntamente com os movimentos sociais que buscam uma educação com qualidade para todos que fazem parte do campo.

A segunda, sobre o histórico da educação do campo, desde a sua criação até a atualidade, mostrou o que para nós era muito claro desde o início, isto é, a concepção sedimentada e equivocada de que o campo é um lugar de atraso, e da forma preconceituosa de como o sujeito do campo é visto. Assim, a partir dessas constatações reafirmamos que homens e mulheres do campo são sujeitos que têm seus direitos e que estes não podem ser esquecidos.Também, porque esses 


\section{CRIAR EDUCAÇÃO}

Revista do Programa de Pós-Graduação em Educação - UNESC

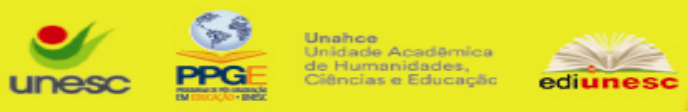

sujeitos carregam uma riqueza cultural e têm valores sociais que não se pode negar, e que são indispensáveis quando tratamos da formação e da educação do campo.

Por último, podemos dizer que a formação de professores para educação do campo ainda é incipiente, mas que o Curso de Licenciatura em Educação do Campo da Universidade Federal de Tocantins (UFT) é uma preparação para que esses profissionais saibam lidar com as realidades do campo, para que o processo educativo seja emancipatório e, sobretudo, político, de modo a que os alunos possam refletir sobre as suas raízes, seus valores, sua comunidade, sua cultura e, assim, terem orgulho da sua identidade. 


\section{CRIAR EDUCAÇÃO}

Revista do Programa de Pós-Graduação em Educação - UNESC

\section{- \\ unesc

\section{REFERÊNCIAS}

ARROYO, MiguelG.; CALDART, RoseliS.; MOLINA, MônicaC. (Orgs.). Por uma educação do campo. 3.ed. Petrópolis (RJ): Vozes, 2008.

BRASIL. DECRETO ก.․ 7.352, DE 4 DE NOVEMBRO DE 2010 - Dispõe sobre a política de educação do campo e o Programa Nacional de Educação na Reforma Agrária - PRONERA. Disponível em <http://portal.mec.gov.br/docman/marco-2012pdf/10199-8-decreto-7352-de4-de-novembro-de-2010/file> Acesso em 25/fev./2016.

BRASIL. Constituição da República Federativa do Brasil de 1988. Brasília (DF): Secretaria da Presidência da República, 1988. Disponível em: <http://presrepublica.jusbrasil.com.br/legislacao/91972/constituicao-da-republicafederativa-do-brasil-1988> Acesso em 08/jun./2016

CALDART, Roseli S. A escola do campo em movimento. In: BENJAMIN, César; CALDART, Roseli Salete. Projeto popular e escolas do campo. Brasília(DF): Articulação Nacional por uma Educação Básica do Campo, 2000.

MARTINS, Fernando José. Educação do Campo: processo social e escolar. 2009. Disponível em <http://www.proceedings.scielo.br/pdf/cips/n2/06.pdf> Acesso em 07/jan./2016

MÉSZAROS, István. A educação para além do capital. Tradução de Isa Tavares. São Paulo:Boitempo, 2005. 